\title{
Aberrant Location of Low-grade Myofibroblastic Sarcoma of the Gingiva in Posterior Maxilla
}

\author{
Neeta S Padmawar ${ }^{1}$, Shivkanya Bhadange ${ }^{2}$, Rachita G Mustilwar ${ }^{3}$, Viddyasagar P Mopagar ${ }^{4}$, Vinay H Vadvadgi ${ }^{5}$, Sourabh R Joshi ${ }^{6}$
}

\begin{abstract}
Low-grade myofibroblastic sarcoma is a malignant tumor arising from myofibroblasts, which has only recently become clearly defined. It represents a rare entity developing in the soft tissues of the head and neck. About 20 cases have been reported in the oral cavity, especially in the tongue and bone, while gingiva as the primary site has been described only twice to date. Diagnostic methods include histology and immunohistochemistry. The present report concerns a case of a 13-year-old female child who presented with gingival nonulcerated swelling that was interpreted for a long time as a gingival fibroma. A low-grade myofibroblastic sarcoma was diagnosed and the patient underwent a segmental osteotomy of the right posterior region of the maxilla. There was no sign of recurrence or metastatic disease during the 12-month postoperative period.
\end{abstract}

Keyword: Fibroma, Gingiva, Immunohistochemistry, Maxilla, Myofibroblastic sarcoma, Posterior

International Journal of Clinical Pediatric Dentistry (2021): 10.5005/jp-journals-10005-2077

\section{BACKGROUND}

Low-grade myofibrosarcoma is one of the rare entities occurring in the oral cavity, consisting of myofibroblasts as principal cells. ${ }^{1}$ Myofibroblasts were spotted in granulation tissue for first time by Gabbiani et al. in 1971, and these are the primary type of cells in certain neoplastic soft-tissue lesions, but occasionally may be observed in the basement membrane of normal epithelial tissues. Sometimes, they are linked with some non-neoplastic tumors such as inflammatory or fibrosing types. ${ }^{2,3}$

Generally, in adults, myofibroblasts are spotted in the periodontal ligaments and around the testicular seminiferous tubules. ${ }^{4}$ These cells originate from resident proximal mesenchymal cells, particularly fibroblasts, and rarely from smooth muscle cells, pericytes, and endothelial cells. ${ }^{5}$ Histopathologically myoblasts can be recognized and present as cigar-shaped, bipolar or stellate cells with nuclei having long, narrow, serrated, or rippled shape. At times, these cells are spotted, as they may be also occurred as squat, elliptical cells, which may be gently shading with hematoxylin and eosin stains with lightly staining cells with well-defined, tiny, and centrally placed nucleus. ${ }^{6}$

Myofibrosarcomas, sarcomas of myofibroblasts, myofibroblast -rich fibrosarcomas, leiomyosarcoma myofibroblastic variant, and spindle-cell sarcomas showing myofibroblastic differentiation are the some synonyms, which were documented for low-grade myofibroblastic sarcomas (LGMSs) scientifically. ${ }^{7}$

The mitotic activity of the tumor cells can vary in severity but abnormal activities are rare. Trunk, abdomen, and pelvis are the frequently reported locations where LGMs are reported..$^{8,9}$ But, the malignant forms are reported in head and neck region specially in the tongue. ${ }^{10}$

This case emphasizes the significance of diagnostic characteristics and clinical manifestations of an uncommon malignant neoplasm of the oral cavity.
1,4,6 Department of Pediatric and Preventive Dentistry, Rural Dental College, Pravara Institute of Medical Sciences (Deemed to be University), Loni (BK), Maharashtra, India

${ }^{2}$ Department of Periodontology, Rajesh Ramdasji Kambe Dental College and Hospital, Akola, Maharashtra, India

3,5 Department of Periodontology, Rural Dental College, Pravara Institute of Medical Sciences (Deemed to be University), Loni (BK), Maharashtra, India

Corresponding Author: Neeta S Padmawar, Department of Pediatric and Preventive Dentistry, Rural Dental College, Pravara Institute of Medical Sciences (University); Loni(BK), Maharashtra, India, Phone: +919923403377 e-mail: opneeta23@gmail.com

How to cite this article: Padmawar NS, Bhadange S, Mustilwar RG, et al. Aberrant Location of Low-grade Myofibroblastic Sarcoma of the Gingiva in Posterior Maxilla. Int J Clin Pediatr Dent 2021;14(6):816-819. Source of support: Nil

Conflict of interest: None

\section{Case Description}

A 13-year-old Indian female child reported to the out-patient department of Pediatric and Preventive Dentistry with complaint of a large mass on buccal surface of right maxillary posterior region. The lesion was present since 1 month and was slowly growing. Patient also reported of discomfort and bleeding on mastication.

Intraoral examination revealed that nontender, hard swelling of $2 \times 3 \mathrm{~cm}$ sized was associated with mesial aspect of maxillary first permanent molar extending till distal aspect of second molar (Fig. 1). Swelling was also involving occlusal surface of second molar and it also displaced the second molar distally. Skin overlying the swelling was normal. Grade II mobility in relation with maxillary first molar was present and maxillary second molar had grade-I

() The Author(s). 2021 Open Access This article is distributed under the terms of the Creative Commons Attribution 4.0 International License (https://creativecommons. org/licenses/by-nc/4.0/), which permits unrestricted use, distribution, and non-commercial reproduction in any medium, provided you give appropriate credit to the original author(s) and the source, provide a link to the Creative Commons license, and indicate if changes were made. The Creative Commons Public Domain Dedication waiver (http://creativecommons.org/publicdomain/zero/1.0/) applies to the data made available in this article, unless otherwise stated. 


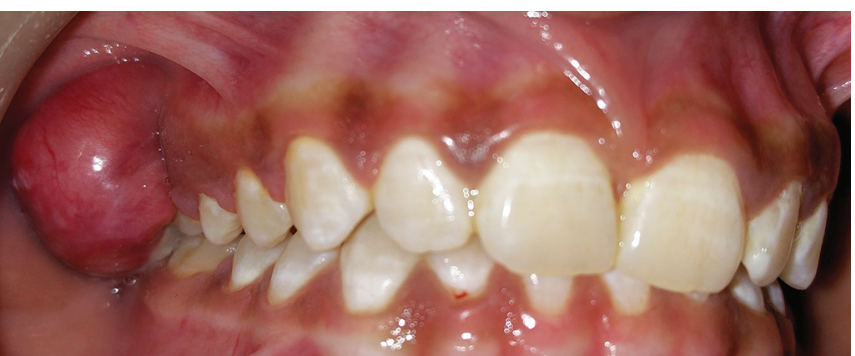

Fig. 1: Intraoral gingival enlargement with tooth 16,1

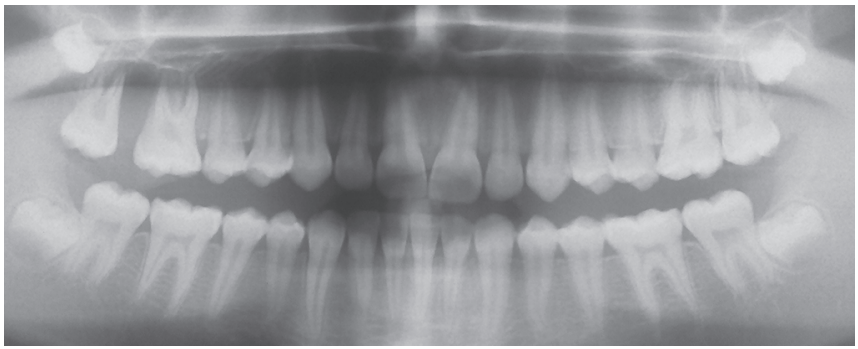

Fig. 2: Osteoprotegerin (OPG) showing bone resorption with distal root of 16

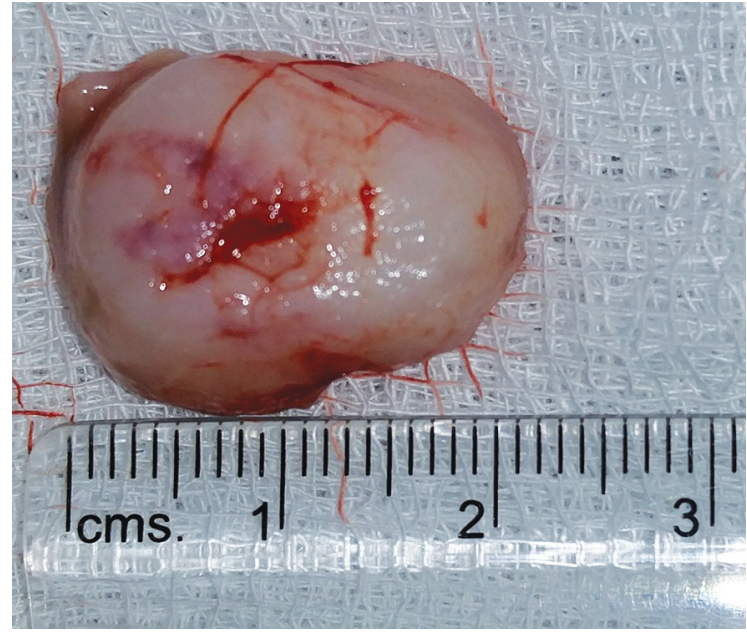

Fig. 3: Excision of soft tissue enlargement

mobility. Medical and menstrual history both were noncontributory. Provisional diagnosis of fibroma was made.

Hematological and radiographic investigations, orthopantomogram (OPG), were made. OPG revealed that severe bone loss was present with distal root of first molar starting from cervical third till apical one-third area (Fig. 2).

Differential diagnosis of fibroma, peripheral giant cell granuloma, and neurofibroma was made.

Excision of the lesion was carried out under local anesthesia; $2 \%$ lignocaine with adrenaline $(1: 80,000)(2 \% \text { Lignox })^{\circ}$ - Posterior Superior Alveolar Nerve Block and Greater Palatine Nerve Block were used. Excision was followed by thorough curettage with Gracey's Curette Number 13, 14 and irrigation with diluted tincture iodine with normal saline was done followed by zinc oxide-COE-PAK ${ }^{\mathrm{TM}}$ (Eugenol free, GC Manufactured) dressing was given. The specimen was sent for histological examination (Fig. 3). Patient was recalled for follow-up after 24 hours and 1 week-no abnormal findings

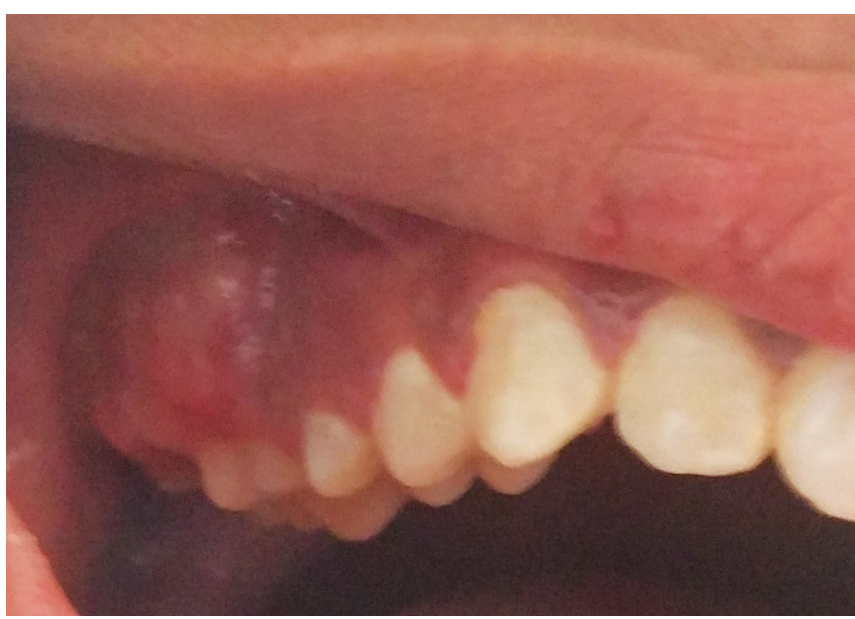

Fig. 4: Recurrence of swelling within 15 days

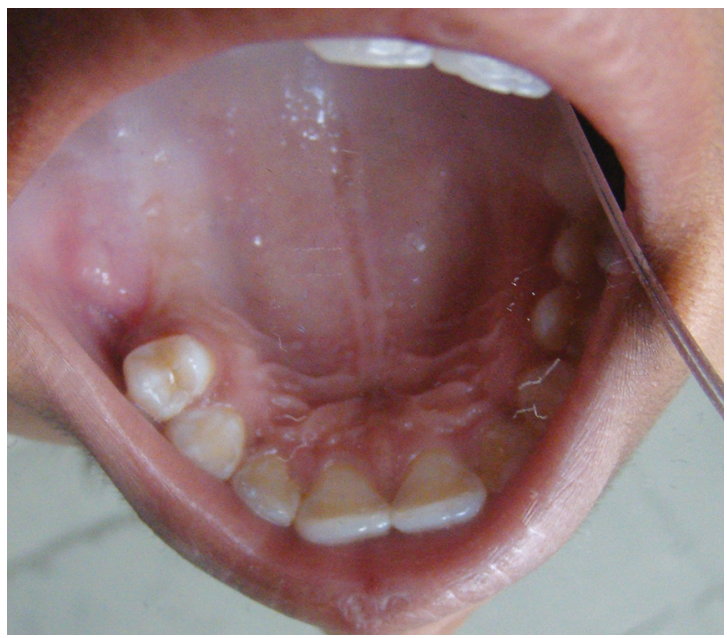

Fig. 5: After 1 year of follow-up, complete healing is seen

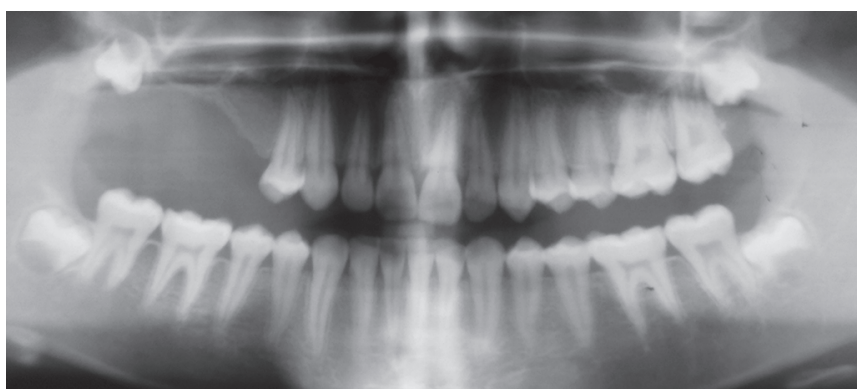

Fig. 6: Osteoprotegerin (OPG) after 1 year of follow-up showed complete healing

were found. But after 15 days, patient came back with complaint of swelling in same region (Fig. 4).

Extraction of maxillary permanent first and second molars along with alveoplasty. The defect was covered with buccal fat pad with overlying closure with a layer of buccal mucosal flap was carried out under general anesthesia. Specimen was sent for histopathological examination.

Patient was under observation for recurrence and metastasis. After 1 year of follow-up, patient was symptom free and wound was healed completely with no sign of metastasis (Figs 5 and 6). 


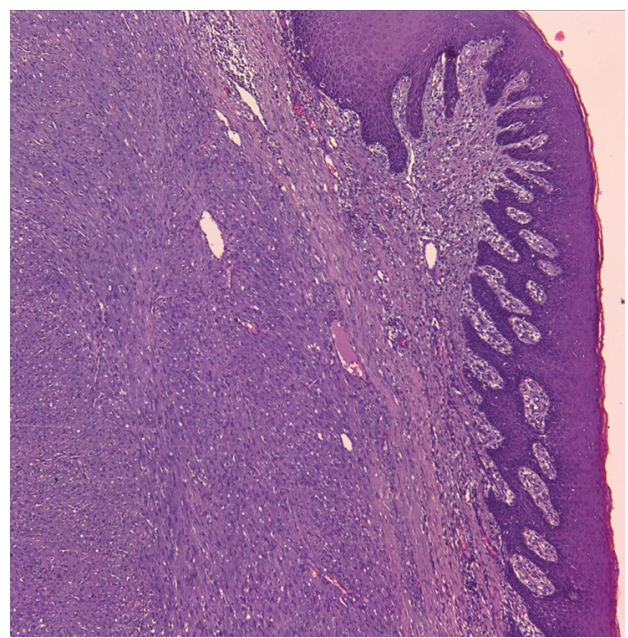

Fig. 7: Hematoxylin and eosin staining showing intact overlying epithelium with neoplastic infiltration

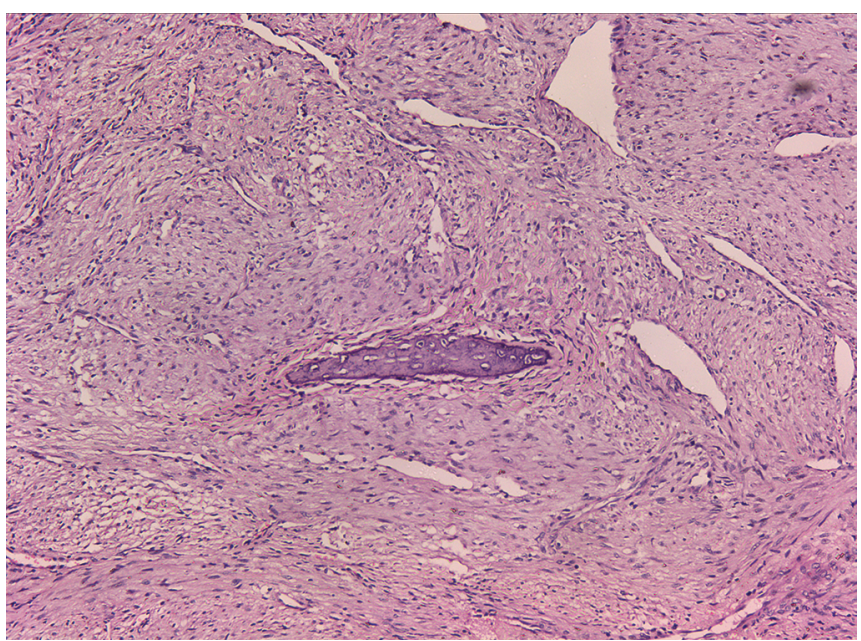

Fig. 8: Hematoxylin and eosin staining showing presence of bone trabeculae

\section{Histological and Immunochemical Examination}

Histologically, the lesion was collection of areas with high-cellular activities. The epithelium lining was ulcerated and showed acute and chronic inflammation (Fig. 7). Neoplastic cells were spindle shaped with elongated, atypical nuclei with prominent nucleoli and eosinophilic cytoplasm. The cells were arranged in a diffusely infiltrative pattern within the gingival mucosa, bone trabeculae were also present (Fig. 8). Neoplastic cells were immersed in myxoid stroma. Focally, necrosis and calcifications were detected.

Immunohistochemically, the neoplastic cells were scatteredly stained with vimentin (Fig. 9), smooth muscles were stained with actin and desmin predominantly. They were cytokeratin, CD34, and CD21 negative.

Immunochemical analysis showed negative response of tumor cells towards S-100 protein (Fig. 10) These all histological findings were indicative of low-grade myofibrosarcoma.

\section{Discussion}

In 1980, Ghadially coined term myofibrosarcoma for malignant tumor arising from myofibroblasts, which was a corresponding term

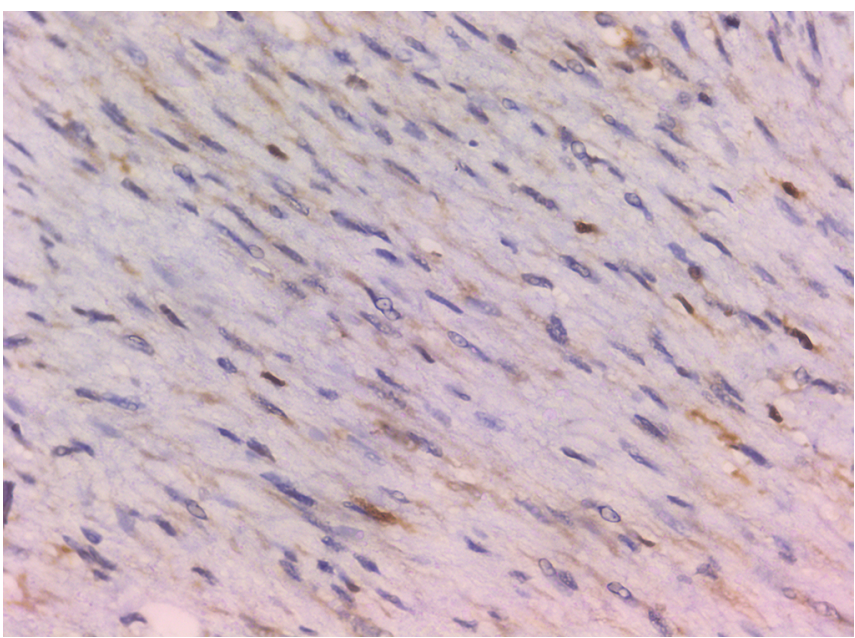

Fig. 9: Vimentine positive

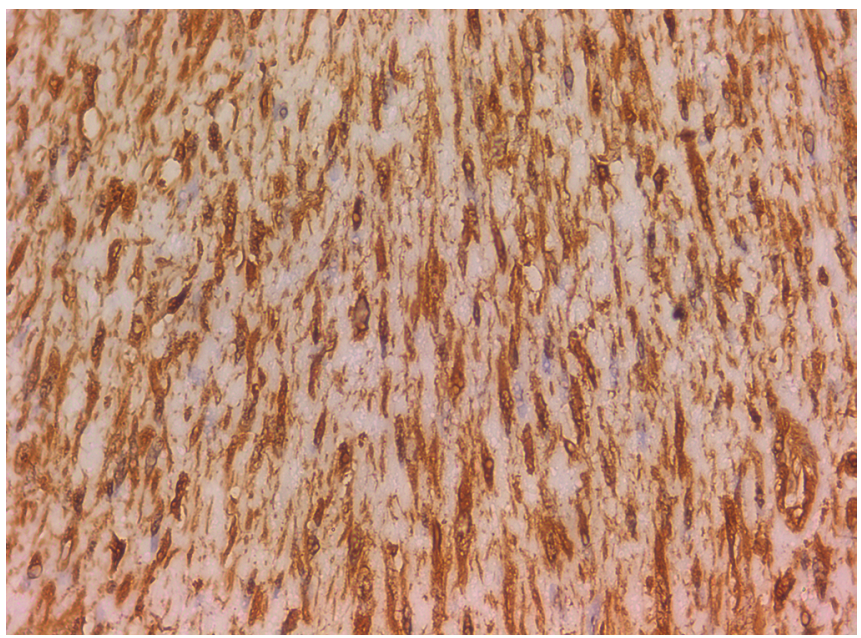

Fig. 10: S-100 negative

of fibrosarcoma. Myofibroblastic sarcomas (myofibrosarcomas) are presently graded as low, intermediate, and high type. ${ }^{11}$

Low-grade myofibroblastic sarcoma is malignant variety of tumor originating due to myofibroblastic differentiation of mesenchyme. This entity can be reported at any age and in either of genders but with a partly male preponderance. In the literature, almost 20 cases of low grade myofibrosarcoma of the oral cavity, mostly involving the tongue and bone area, have been documentated. ${ }^{1}$ But, only one case of gingival origin has been illustrated so far which was in mandibular anterior region. ${ }^{12}$ The placement of this kind of tumor in the gingiva is unfamiliar and unusual and in our patient the location was very rare which is maxillary posterior region.

Patients with LGMS have been reported in all age duration from 4-85 years with mean of 40 years and male showed high predomination slightly. The dimensions of these tumor vary from $1.5-17 \mathrm{~cm}^{13}$

Clinically, it is present as a painless, slow-growing mass with little pain sometime course and overlying epithelium does not show any changes or break in continuity, which contributes to delayed diagnosis and further worsening prognosis.' But, present case was reported in female in early teen age and posterior region. 
Presence of continued normal epithelium increases the peril of late diagnosis and thus affecting the prognosis adversely. Detection of these myofibroblastic sarcomas is very difficult as the tumor surface appears with normal overlying mucosal surface clinically, but in literature, some cases were reported with the lasting nonhealing ulceration on overlying mucosal surface. ${ }^{14}$ Present case had normal overlying mucosa, which gave presentation of fibroma.

Detection of osteolytic and bone destructive process at the location of lesion can be supportive in the diagnosis, ${ }^{14}$ but in our patient, though the tumor mass was so close to the bone, no bone involvement was detected clinically. Histopathological and immunohistochemical analyses are the requisites for the confirmatory diagnosis. ${ }^{13,14}$ During the incisal biopsy, depth of the specimen should involve sufficient submucosal thickness, as it can contribute the outcome. As specimen from tumor surface may show presence of granulation tissue such as structures and hypocellular zones but not the atypical hypercellular patches. ${ }^{3,14}$ Fine-needle aspiration biopsy might be noncontributory.

\section{Conclusion}

The clinical presentation of myofibrosarcomas is strenuous to distinguish it from other mesenchymal tumors. Histological and immunohistochemical analysis investigations play prime role in diagnosis of these tumors. Therapeutic goals should include the surgical removal of the lesion, functional, and esthetic rehabilitation of the patient thus affecting the quality of the patient's life positively. Long-term follow-up is needed.

\section{References}

1. Jay A, Piper K, Farthing PM, et al. Low-grade myofibroblastic sarcoma of the tongue. Oral Surg Oral Med Oral Pathol Oral Radiol Endod 2007;104:52-58. DOI: 10.1016/j.tripleo.2007.06.004
2. Gabbiani G, Ryan GB, Majne G. Presence of modified fibroblasts in granulation tissue and their possible role in wound contraction. Experientia 1971;27:549-550. DOI: 10.1007/BF02147594

3. Schürch W, Seemayer TA, Gabbiani G. The myofibroblast: a quarter century after its discovery. Am J Surg Pathol 1998;22:141-147. DOI: 10.1097/00000478-199802000-00001

4. Eyden BP, Ponting J, Davies $\mathrm{H}$, et al. Defining the myofibroblast: normal tissues, with special reference to the stromal cells of Wharton's jelly in human umbilical cord. J Submicrosc Cytol Pathol 1994;26:347-355. PMID: 8087799.

5. Schürch W, Seemayer TA, Hinz B, et al. Myofibroblast. In: Histology for Pathologists, 3rd edition. Mills SE (ed). Philadelphia, PA: Lippincott, Williams \& Wilkins 2006.

6. Fisher C. Myofibroblastic malignancies. Adv Anat Pathol 2004;11:190-201. DOI: 10.1097/01.pap.0000131773.16130.aa

7. Morgan PB, Chundru S, Hatch SS, et al. Uncommon malignancies: case 1. Low-grade myofibroblastic sarcoma of the breast. J Clin Oncol. 2005;23:6249-6251. DOI: 10.1200/JCO.2005.06.213

8. Fisher C. Myofibrosarcoma. Virchows Arch 2004;445:215-223. DOI: 10.1007/s00428-004-1038-9

9. Gonzalez-Palacios F, Enriquez JL, San Miguel P, et al. Myofibroblastic tumors of the breast: a histologic spectrum with a case of recurrent male breast myofibrosarcoma. Int J Surg Pathol 1999;7:11-17. DOI: $10.1177 / 106689699900700102$

10. Montebugnoli L, Venturi M, Gissi DB, et al. Low-grade myofibroblastic sarcoma of the gingiva. BMJ Case Rep 2010. DOI: $10.1136 /$ bcr.07.2010.3166

11. Ghadially FN. Diagnostic electron microscopy of Tumors. London: Butterworth \& Co., Ltd 1980.

12. Montgomery E, Goldblum JR, Fisher C. Myofibrosarcoma: a clinicopathologic study. Am J Surg Pathol 2001;25:219-228. DOI: 10.1097/00000478-200102000-00010

13. Qiu JY, Liu P, Shi C, et al. Low-grade myofibroblastic sarcomas of the maxilla. Oncol Lett 2015;9:619-625. DOI: 10.3892/ol.2014.2790

14. Demarosi F, Bay A, Moneghini L, et al. Low-grade myofibroblastic sarcoma of the oral cavity. Oral Surg Oral Med Oral Pathol Oral Radiol Endod 2009;108:248-254. DOI: 10.1016/j.tripleo.2009.03.031 